\section{Effects of Leucocyanidines on Activities of Metabolizing Enzymes and Antioxidant Enzymes}

Kyungwon Seo, ${ }^{*, a}$ Soonyoung JunG, ${ }^{b}$ Mijung PARK, ${ }^{a}$ Yeonjung SonG, ${ }^{a}$ and Seyoung $\mathrm{CHOUNG}^{b}$

Toxicology Department, National Institute of Toxicological Research, Korea Food and Drug Administration, ${ }^{a} 5$ Nokbundong, Eunpyunggu, Seoul 122-704, Korea and College of Pharmacy, Kyunghee University, 1 Hoegidong, Dongdaemoonku, Seoul 137701, Korea. Received December 25, 2000; accepted March 2, 2001

Procyanidolic oligomers (leucocyanidines, LCs) extracted from grape seeds (Vitis vinifera) are known to have antioxidant and antimutagenic activities, and a protective effect against cardiovascular disease. In the present study we examined the influence of LCs on the activities of phase I enzymes and conjugation enzymes and on antioxidant enzymes such as superoxide dismutase, catalase, and glutathione peroxidase. Administration of LCs $(25,50$, and $100 \mathrm{mg} / \mathrm{kg}$. p.o. for $7 \mathrm{~d})$ markedly decreased the activities of NADPH-cytochrome $\mathbf{P 4 5 0}$ reductase, P4501A1, P4501A2, and P4503A4, but significantly increased the activities of glutathione $S$-transferase and phenolsulfotransferase in rat liver. However, the activities of antioxidant enzymes were not affected by LC administration. The inhibition of P450s and increases in phase II enzyme activities indicate a role for LCs as a chemopreventive agent against toxic or carcinogenic metabolites of $\mathbf{P 4 5 0}$ isozymes.

Key words leucocyanidine; metabolizing enzyme; antioxidant enzyme

Grape seed (Vitis vinifera) extracts are known to be potent antioxidants and contain numerous polyphenols. The standardized grape seed extract, procyanidolic oligomers (leucocyanidines) was used in this study. Leucocyanidines (LCs) consist of a monomeric molecule (flavane-3,4-diol LC, Fig. 1) and its oligomers. ${ }^{1)}$ The procyanidolic oligomers from $V$. vinifera seed have been shown to have positive effects on vascular injury, ${ }^{1)}$ and are also known to have free radicalscavenging ${ }^{2,3)}$ and antimutagenic activity.

In a recent publication, it has been reported that the grape/leaf juice of $V$. vinifera reduces mycotoxin-induced hepatic damage and the formation of hepatoma. ${ }^{5)}$ Although the mechanisms of chemoprotection remain poorly understood, the activity of most chemopreventive agents is believed to be related to their ability to alter expression of phase I and/or phase II drug-metabolizing enzymes. ${ }^{6,7)}$

In the present study, we examined the influence of LCs on the activities of phase I enzymes and conjugation enzymes. The activities of antioxidant enzymes such as superoxide dismutase (SOD), catalase, and glutathione peroxidase (GPx) were also measured, because trapping of electrophiles and free radicals is a possible mechanism of various chemopre-<smiles>Oc1cc(O)c2c(c1)OC(c1ccc(O)c(O)c1)C(O)C2O</smiles>

Fig. 1 ventors. ${ }^{8)}$

\section{MATERIALS AND METHODS}

Chemicals Commercial standardized procyanidolic oligomers (LCs, Leucoselect ${ }^{\circledR}$ ) produced by Indena (Milan, Italy) were used in this study.

Animal Treatment Male Sprague-Dawley rats (180$220 \mathrm{~g}$ ) were obtained from the Korea Food and Drug Administration (Seoul, Korea). Rats were administered LCs orally $(25,50,100 \mathrm{mg} / \mathrm{kg})$ in propylene glycol for 7 consecutive days.

Enzyme Assays The activities of NADPH-cytochrome P450 reductase (NADPH-R) and pentoxyresorufin $O$-dealkylase (P4502B1) were determined using published procedures. ${ }^{9}$ 10) Ethoxyresorufin $O$-dealkylase (P4501A1) and methoxyresorufin $O$-dealkylase (P4501A2) activities were measured in exactly the same manner as the assay for P4502B1, except for the substrates used. ${ }^{11,12)}$ The activities of $N$-nitrosodimethylamine $N$-demethylase (P4502E1) and erythromycin $N$-demethylase (P4503A4) were assayed based on the procedures described by Sohn et al. and Fabre et $a l^{13,14)}$ UDP-glucuronyltransferase (UDP-GT) and glutathione $S$-transferase (GST) activities were determined using the procedure of Bock et al. and Habig et al., respectively. ${ }^{15,16)}$ Phenolsulfotransferase (PST) was measured colorimetrically according to the method of Sekura and Jakoby. ${ }^{17)}$ GPx activity and catalase activity were determined using published methods. ${ }^{18,19)}$ SOD activity was determined using a SOD kit (OXIS International, Inc., U.S.A.).

Statistical Analysis One-way analysis of variance was used to assess the statistical significance of changes in all indices, followed by Duncan's multiple range test, with $p<0.05$ set at the minimum level of significance by SPSS-PC + .

\section{RESULTS}

The effects of LCs on the activities of metabolizing enzymes in rats are shown in Table 1. After administration of LCs, major findings were in the phase I enzyme system. Most hepatic P450 monooxygenases were inhibited in rats that received LCs. The activities of P4501A1 and P4501A2 were markedly decreased to $55 \%$ and $44 \%$ of the control level after LC administration, respectively. NADPH-R activity was also inhibited to about $71 \%$ of the control level in LC-treated rats. A smaller, but significant decrease was observed in the activity of P4503A4 (77\% of control). The activities of P4502B1 and P4502E1 were also slightly decreased in rats that received LCs, but these changes were not statistically significant. Among the phase II enzymes, UDPGT activity was markedly decreased (68\% of control) in the LC-treated group. However, LCs caused significant increases in both GST activity and PST activity to 1.2 -fold those in the control rats. The influence of LCs on the activities of antioxidant enzymes was also investigated in rat liver. Little or no change in the activities of GPx, SOD, and catalase were observed in rat livers administered LCs $25-100 \mathrm{mg} / \mathrm{kg}$ LCs. 
Table 1. Effect of LCs on the Activities of Metabolizing Enzymes and Antioxidant Enzymes in Rats ${ }^{a, b)}$

\begin{tabular}{clcccc}
\hline \hline \multirow{2}{*}{ Enzyme } & & Control & $25 \mathrm{mg} / \mathrm{kg}$ & $50 \mathrm{mg} / \mathrm{kg}$ & $100 \mathrm{mg} / \mathrm{kg}$ \\
\hline \multirow{2}{*}{ Phase I } & NADPH-R & $53.3 \pm 8.13$ & $46.3 \pm 7.08$ & $42.9 \pm 3.84^{*}$ & $38.1 \pm 6.53^{*}$ \\
& 1A1 & $13.0 \pm 4.60$ & $18.7 \pm 3.65$ & $15.6 \pm 3.16$ & $7.2 \pm 2.56^{*}$ \\
& 1A2 & $7.3 \pm 4.07$ & $7.8 \pm 2.84$ & $8.0 \pm 1.55$ & $3.2 \pm 1.86^{*}$ \\
& 2B1 & $7.9 \pm 4.24$ & $8.9 \pm 2.99$ & $8.0 \pm 1.18$ & $4.4 \pm 2.37$ \\
& 3A4 & $14.2 \pm 3.01$ & $13.0 \pm 2.79$ & $11.9 \pm 1.71^{*}$ & $11.0 \pm 1.85^{*}$ \\
& 2E1 & $0.28 \pm 0.035$ & $0.31 \pm 0.051$ & $0.29 \pm 0.032$ & $0.26 \pm 0.026$ \\
Phase II & UDP-GT & $5.0 \pm 0.73$ & $4.7 \pm 1.15$ & $3.9 \pm 0.42^{*}$ & $3.4 \pm 0.48^{*}$ \\
& PST & $5.9 \pm 0.71$ & $5.8 \pm 1.16$ & $5.8 \pm 0.16$ & $7.0 \pm 1.44^{*}$ \\
& GST & $0.66 \pm 0.082$ & $0.72 \pm 0.060$ & $0.73 \pm 0.083$ & $0.77 \pm 0.111^{*}$ \\
& GPx & $4.4 \pm 0.30$ & $4.3 \pm 0.41$ & $4.1 \pm 0.26$ & $4.3 \pm 0.42$ \\
& SOD & $15.8 \pm 1.62$ & $15.1 \pm 1.18$ & $16.4 \pm 0.92$ & $16.1 \pm 1.14$ \\
& Catalase & $47.0 \pm 1.62$ & $45.5 \pm 7.84$ & $45.1 \pm 5.47$ & $49.6 \pm 4.12$ \\
& & & & &
\end{tabular}

a) The activities of NADPH-R, phase I enzymes, and UDP-GT were estimated in the microsomal fraction. The activities of PST and GST, GPx, SOD, and catalase were measured in cytosolic suspensions. Values are expressed as mean \pm S.D. of 8 rats. b) Enzyme activities are expressed as follows: 1A1, 1A2, 2B1, resorufin (pmol) produced $/ \mathrm{min} / \mathrm{mg}$ protein; $2 \mathrm{E} 1,3 \mathrm{~A} 4$, formaldehyde (nmol, $\mathrm{pmol}$ ) produced $/ \mathrm{min} / \mathrm{mg}$ protein; UDP-GT, $p$-nitrophenol (nmol) consumed $/ \mathrm{min} / \mathrm{mg}$ protein; PST, $\beta$-naphthyl sulfate $(\mathrm{nmol})$ formed $/ \mathrm{min} / \mathrm{mg}$ protein; GST, CDNB-GS $(\mu \mathrm{mol})$ formed $/ \mathrm{min} / \mathrm{mg}$ protein; $\mathrm{SOD}$, unit $/ \mathrm{mg}$ protein; catalase, $\mathrm{H}_{2} \mathrm{O}_{2}(\mathrm{mmol})$ consumed $/ \mathrm{min} / \mathrm{mg}$ protein; $\mathrm{GPx}$, NADPH $(\mu \mathrm{mol})$ oxidized $/ \mathrm{min} / \mathrm{mg}$ protein. $*$ Significantly different from control rats at $p<0.05$.

\section{DISCUSSION}

It is well established that most chemical carcinogens require metabolic activation before exerting their carcinogenic effects. The activated carcinogens are usually electrophilic agents and are highly reactive with DNA molecules. In theory, chemical carcinogenesis can be prevented, in most cases, by blocking the metabolic activation process. Since P450 enzymes play key roles in the activation of most carcinogens, inhibition on P450s provides protection. It is also known that certain chemicals, many of which have a dietary origin, can inhibit the activities of P450 enzymes selectively, thus providing the opportunity for selective inhibition of the carcinogenicity and toxicity of known chemicals by specific inhibitors of P450 enzymes. ${ }^{20)}$ In this study, administration of LCs markedly decreased the activities of P4501A1, 1A2, and $3 \mathrm{~A} 4$, thus potentially altering the metabolism of substrates for these enzymes. Since these enzymes catalyze the activation of numerous protoxicants and procarcinogens, by inhibiting these isozymes LCs may act as chemoprotective agents against toxic substances or metabolites that exert their effect at other tissue sites. With inhibition of P450s, an increase in phase II activities can be an important protective mechanism. Conjugation with GSH represents an important detoxification reaction. It is known that the reactive metabolites of carcinogens or toxicants are normally detoxified by glutathione conjugation. Sulfation is also major detoxification reaction involved in metabolic conversion of endogenous and exogenous substances to more aqueous-soluble compounds that can be excreted. The glutathione conjugation is mediated by GST, and sulfation is dependent upon the activity of sulfotransferase in the cytosol. Increases in activities of phase II detoxication enzymes, such as GST and PST, in rodent tissues afford protection against carcinogens and other toxic electrophiles. In recent studies, we have found that increases in the activities of GST and ST enhance the conjuga- tion with GSH and sulfate, resulting in a decrease in acetaminophen-induced toxicity in rats. ${ }^{21,22)}$ Therefore increases in the activities of PST and GST by LCs may have a significant role in protection against carcinogenesis and toxic effects. Together with the inhibition of P450s and increased activities of PST and GST, the present study clearly demonstrates the selective effects of LCs on various xenobiotic-metabolizing enzymes. The selective effects of LCs on different xenobiotic-metabolizing enzymes suggest that they can be used as chemopreventive agents against toxic or carcinogenic metabolites of P450 isozymes without resulting in general inhibition of all enzymes. Cancer chemoprevention studies have shown that following the administration of chemopreventive agents, the levels of antioxidant enzymes are elevated in various organs of test animals. ${ }^{23)}$ In our study of antioxidant enzymes, the activities of SOD, catalase, and GPx were not influenced by LC treatment. Therefore the role of these enzymes in the chemopreventive effect of LCs is not discussed here. However, the insignificant effects of LCs on antioxidant enzymes indicate that LCs do not generate oxidative stress.

\section{REFERENCES}

1) Masquelier J., Perfumes, Cosmetiques, Aromes, Oct.-Nov., 89-97 (1997).

2) Facino R. M., Carini M., Aldini G., Bombardelli E., Morazzoni P., Morelli R., Drug Res., 44, 592-601 (1994).

3) Nuttall S. L., Kendall M. J., Bombardelli E., Morazzoni P., J. Clin. Pharm. Ther, 23, 385-389 (1998).

4) Morazzoni P., Bombardelli E., Fitoterapia, LXV, 203-208 (1994).

5) Jesval P., Cytobios, 93, 123-128 (1998).

6) Wang E. J., Li Y., Lin M., Chen L., Stein A. P., Reuhl K. R., Yang C. S., Toxicol. Appl. Pharmacol., 136, 146-154 (1996).

7) Ahn D., Putt D., Kresty L., Stoner G. D., Fromm D., Hollenberg P. F., Carcinogenesis, 17, 821-828 (1996).

8) Stavric B., Food Chem. Toxicol., 32, 79-90 (1994).

9) Lake B. G., "Biochemical Toxicology; A Practical Approach," IRL Press, Oxford, 1987, pp. 200-201.

10) Burke M. D., Mayer R. T., Drug Metab. Dispos., 2, 583-588 (1974).

11) Lubet R. A., Mayer R. T., Cameron J. W., Nims R. W., Burke M. D., Wolff T., Guengerich F. P., Arch. Biochem. Biophys., 238, 43-48 (1985).

12) Nerukar P. V., Park S. S., Thomas P. E., Lubet R. A., Proc. Am. Assoc. Cancer Res., 34, 156 (1993).

13) Sohn O. S., Fiala E. S., Puz C., Hamilton S. R., Williams G. M., Cancer Res., 47, 3123-3129 (1987).

14) Fabre I., Fabra G., Marel P., Bertaultperes P., Cano J. P., Drug Metab. Dispos., 16, 296-301 (1988).

15) Bock K. W., Burchell B., Dutton G. J., Hanninen O., Mulder G. J., Owens I. S., Siest G., Tephly T. R., Biochem. Pharmacol., 32, 953955 (1983).

16) Habig W. H., Pabst M. J., Jakoby W. B., J. Biol. Chem., 249, 71307139 (1974)

17) Sekura R. D., Jakoby W. B., J. Biol. Chem., 254, 5658-5663 (1979).

18) Duan Y. J., Kumyra S., Fiszer A. B., Szafarz D., Yagi K., J. Biol. Chem., 263, 19003-19008 (1988).

19) Carrillo M. C., Kanai S. K., Sato Y., Ivy G. O., Kitani K., Biochem. Pharmacol., 44, 2185-2189 (1992).

20) Yang C. S., Brady J. F., Hong, J.-Y., FASEB J., 6, 737-744 (1992).

21) Seo K. W., Kim J. G., Park M., Kim T. W., Kim H. J., Xenobiotica, 30, $535-540$ (2000).

22) Seo K. W., Oh M. H., Choung S. Y., Kim S. J., Kim H. J., Biol. Pharm. Bull., 22, 261-264 (1999).

23) Wattenberg L. W., "Antimutagenesis and Anticarcinogenesis, Mechanisms II,” Plenum Publishing Corp., New York, 1990, pp. 155-166. 